\title{
A set of 400 pictures standardized for French: Norms for name agreement, image agreement, familiarity, visual complexity, image variability, and age of acquisition
}

\author{
F.-XAVIER ALARIO and LUDOVIC FERRAND \\ CNRS and Université René Descartes, Paris, France
}

\begin{abstract}
The present article provides French normative measures for 400 line drawings taken from Cycowicz, Friedman, Rothstein, and Snodgrass (1997), including the 260 line drawings that were normed by Snodgrass and Vanderwart (1980). The pictures have been standardized on the following variables: name agreement, image agreement, familiarity, visual complexity, image variability, and age of acquisition. These normative data also include word frequency values and the first verbal associate (taken from Ferrand \& Alario, 1998). The six variables obtained are important because of their potential effect in many fields of psychology, especially the study of cognitive processes such as visual perception, language, and memory.
\end{abstract}

In recent years, experiments employing pictures of objects have proliferated. However, little standardization of line drawings exists. To date, each investigator has been forced to develop his or her own set of pictures, which are necessarily highly idiosyncratic (Snodgrass, LevyBerger, \& Haydon, 1985). One exception is the pioneering work of Snodgrass and Vanderwart (1980). These authors have provided a set of 260 pictures (black-andwhite line drawings) that have been standardized on four variables of relevance to experimentation in visual perception, language, and memory. The four variables collected were name agreement (the degree to which subjects agree on the name of the picture), image agreement (the degree to which images generated by subjects to a picture's name agree with the picture's appearance), familiarity (the familiarity of the concept depicted), and visual complexity (the amount of lines and details in the drawing). These normative data for pictures were collected in American English for young adults.

Since then, other normative data for pictures have been collected by Berman, Friedman, Hamberger, and Snodgrass (1989) for 5- and 6-year-old children and by Cycowicz, Friedman, Rothstein, and Snodgrass (1997) for 8to 10 -year-old children. More recently, these normative

This research was supported by a grant from the Direction de la Recherche et de la Technologie (a division of the Direction Générale de l'Armement) to the first author. We are grateful to Robert Proctor, Joan Gay Snodgrass, Carmen Sanfeliu, Ronald Peereman, and Juan Segui for helpful feedback on an earlier version of this manuscript. Thanks are extended to Carmen Sanfeliu for sending the set of data for Spanish and English. Correspondence concerning this article should be addressed to F.-X. Alario or to L. Ferrand, CNRS and Université René Descartes, Laboratoire de Psychologie Expérimentale, 28 rue Serpente, 75006 Paris, France (e-mail: alario@psycho.univ-paris5.fr or ferrand@ psycho.univ-paris5.fr). data have also been collected for adults in British English (Barry, Morrison, \& Ellis, 1997; Vitkovitch \& Tyrrell, 1995), in Spanish (Sanfeliu \& Fernández, 1996), and in Dutch (Martein, 1995). However, to our knowledge, there is no such normative database available in French. Because it is vital for the experimenter to have as much control of the experimental situation as possible, careful selection of stimuli is necessary. The present article provides normative measures for 400 line drawings and their corresponding names viewed by French-speaking young adults.

When available, these normative studies have been extremely useful in many fields of psychology, including memory and language, through the use of different kinds of subjects (e.g., children, adults, and pathological cases). Concerning the study of language, for instance, these databases have been used to study the processes involved in picture naming (e.g., Ferrand, Grainger, \& Segui, 1994; Ferrand, Humphreys, \& Segui, 1998; Humphreys, Lamote, \& Lloyd-Jones, 1995; Johnson, Paivio, \& Clark, 1996; Snodgrass \& Yuditsky, 1996) and, more generally, in speech production (e.g., Ferrand \& Segui, 1998; Ferrand, Segui, \& Grainger, 1996). These normative data have also been very useful in the fields of perceptual identification and recognition (e.g., Kroll \& Potter, 1984; Snodgrass \& Poster, 1992) and implicit memory (e.g., Feenan \& Snodgrass, 1990; Hirshman, Snodgrass, Mindes, \& Feenan, 1990; Snodgrass \& Feenan, 1990; Snodgrass, Smith, Feenan, \& Corwin, 1987; Snodgrass \& Surprenant, 1989).

The motivation for the present study was to obtain a normative database for pictorial material that will be useful for future studies with French-speaking subjects. We conducted a study in which the stimuli were the 400 pictures used by Cycowicz et al. (1997), including the 260 line drawings that were normed by Snodgrass and Van- 
derwart (1980). In closely following Snodgrass and Vanderwart's procedure, norms for name agreement, image agreement, picture familiarity, visual complexity, image variability, and age of acquisition were collected. The normative database also include the most common name given to each of the 400 concepts (modal name), word frequency (taken from Content, Mousty, \& Radeau, 1990 ), and the first verbal associate of the names of the pictures (taken from Ferrand \& Alario, 1998).

In what follows, we briefly discuss empirical findings related to each variable. Name agreement refers to the degree to which subjects agree on the name of the picture. This information is important for naming latency studies, picture-name matching studies, recall memory studies, and recognition studies in which verbal encoding is manipulated. Name agreement is measured by the number of different names given to a particular picture across subjects. Pictures that elicit many different names have lower name agreement than those eliciting a single name. Name agreement is a robust predictor of naming difficulty. Pictures with a single dominant response are named more quickly and accurately than those with multiple responses (Barry et al., 1997; Lachman, Shaffer, \& Hennrikus, 1974; Paivio, Clark, Digdon, \& Bons, 1989; Vitkovitch \& Tyrrell, 1995). More important, name agreement affects naming independently of the effects of correlated attributes, such as word frequency and rated age of name acquisition (Lachman et al., 1974).

Image agreement refers to the degree to which images generated by subjects to a picture's name agree with the picture's appearance. Barry et al. (1997) showed that pictures with higher ratings of image agreement were named faster than were those with lower ratings. They suggested that image agreement has its influence at the level of object recognition, so that the closer a picture is to one's mental image of an object, the faster the naming time for that item will be.

Familiarity refers to the familiarity of the concept depicted. Familiarity has been shown to have important effects on various memory and cognitive processing tasks (see, e.g., Gernsbacher, 1984). In particular, Snodgrass and Yuditsky (1996) and Feyereisen, Van der Borght, and Seron (1988) showed that rated familiarity is an important predictor of picture-naming latencies, so that the more familiar a concept is, the faster the naming time for that item will be.

Visual complexity refers to the amount of lines and details in the drawing. It is supposed to determine the ease of processing at or before the structural stage of object recognition. Visual complexity may affect such variables as naming latencies, tachistoscopic recognition thresholds, and memorability. Early research using pictorial stimuli has established that, when complexity is manipulated, more complex stimuli are more difficult to process than simple stimuli (Attneave, 1957; Ellis \& Morrison, 1998). However, other investigators showed that complex objects are identified and named as readily as sim- ple objects (Biederman, 1987; Paivio et al., 1989; Snodgrass \& Corwin, 1988; Snodgrass \& Yuditsky, 1996).

For frequency and age of acquisition, picture-naming latencies decrease as name frequency increases (Oldfield \& Wingfield, 1965) and increase as age of word acquisition increases (Carroll \& White, 1973; Ellis \& Morrison, 1998). It is possible that the influence of word frequency on learning, memory, and perception depends on another attribute, such as the age at which the particular word was first learned. Some investigators (Carroll \& White, 1973; Ellis \& Morrison, 1998; Morrison, Chappell, \& Ellis, 1997; Morrison, Ellis, \& Quinlan, 1992) suggested that age of acquisition is a more important variable than frequency in print. However, Barry et al. (1997) and Snodgrass and Yuditsky (1996) found that the time taken to name a pictured object correctly was affected both by rated age of acquisition and by the frequency of the name (in accordance with Lachman, 1973; Lachman et al., 1974). Interestingly, Barry et al. (1997) showed that the age-of-acquisition effect interacted with frequency, the age-of-acquisition effect being more pronounced for pictures with low-frequency names.

\section{METHOD}

\section{Subjects}

A total of 173 students from introductory courses in psychology from the Ecole des Psychologues Praticiens and from Université René Descartes in Paris participated in the study. Different subjects participated in each of the six tasks. There were 28 in the name agreement task, 30 in the image agreement task, 30 in the familiarity task, 29 in the visual complexity task, 30 in the image variability agreement task, and 26 in the age-of-acquisition task. All the subjects were native French speakers and participated voluntarily as a course activity. The subjects were run in groups of from 26 to 30 in a classroom.

\section{Materials}

The pictures were the 400 black-and-white line drawings of common objects taken from Cycowicz et al. (1997). These pictures were downloaded from the Internet (http://www.nyspi.cpmc.columbia. edu/nyspi/respaprs/picnorm.htm). Some of the original line drawings $(n=7)$ were replaced for obvious reasons: The pictures had been selected in the American context (things such as a baseball bat, a football helmet, or a pretzel are more familiar to English speakers in America than to French speakers in France). In particular, we replaced the following drawings (a baseball bat, a football, a football helmet, a fishing reel, a grocery bag, a baseball glove, and a pretzel) by drawings of objects more common in the French speakers' realm of experience (a ski, a French croissant, a motorbike helmet, a swimsuit, a rugby ball, a fishing rod, and a supermarket caddie). These seven pictures were adapted from two French books of pictures (Des Mots en Images, 1988; L'imagier du Père Castor, 1991; they are available on request).

\section{Procedure}

The procedure closely followed the steps described by Snodgrass and Vanderwart (1980) and by Morrisson et al. (1997; for age of acquisition), both in terms of the tasks performed and in the way the tasks were done.

The name agreement task, the image agreement task, the familiarity task, and the complexity task were run in a similar way. However, for the image variability task and the age-of-acquisition task, 
the modal name of the object (instead of the object itself) was presented to the subjects. The 400 pictures were projected sequentially on a large white screen at the front of a slightly darkened room, using an overhead projector. At the beginning of each task, the subjects were read the instructions and encouraged to answer carefully and consistently. They were given individual answer sheets and instructed to respond to every drawing. They were informed of the general nature of the pictures - that is, that they were relatively simple black-and-white outline drawings. Each slide was presented for a period of $5 \mathrm{sec}$. Halfway through the slides, the subjects were given a $15-\mathrm{min}$ rest period. The total amount of time was about $11 / 2 \mathrm{~h}$.

In the name agreement task, the subjects were instructed to identify the drawing with the first name that came to mind and to write the name on the answer sheet. They were told that a name could consist of more than one word. If that was not possible, they had to indicate whether the reason was don't know the object (DKO), don't know the name (DKN), or tip of the tongue (TOT).

In the image agreement task, the subjects were asked to judge how closely each picture resembled their mental image of the object. Prior to presenting each picture, the experimenter called out the picture's most common name, waited approximately $5 \mathrm{sec}$, and then projected the picture on the screen. During the 5-sec period, the subjects looked at the blank screen and formed their mental image of the named object. Following the appearance of the picture on the screen, the subjects rated the degree of agreement between their image and the picture, using the 5-point scale. A rating of 1 indicated low agreement, that the picture provided a poor match to their image, and a rating of 5 indicated high agreement.

In the familiarity task, the subjects were asked to judge the familiarity of the concept of each picture "according to how usual or unusual the object is in your realm of experience." Familiarity was defined as "the degree to which you come in contact with or think about the concept." They were told to rate the concept itself, rather than the way it was drawn. Their answer to each item was again a whole number from a 5-point scale $(1=a$ very unfamiliar object, $5=a$ very familiar object ). The subjects were encouraged to employ the full range of scale values throughout the set of pictures.

The visual complexity task required the subjects to rate the complexity of each drawing, rather than the complexity of the object it represented. They also had to provide ratings from a 5-point scale $(1=$ drawing very simple, $5=$ drawing very complex $)$. Complexity was defined as the amount of details or the intricacy of the lines in the picture.

The two remaining tasks (image variability and age of acquisition) consisted of judgments on the names of the pictures. No overhead projector was used here. The subjects were given a four-page booklet with the 400 names of the pictures. In the image variability task, they were instructed to rate on a 5-point scale $(1=$ few images, $5=$ many images) whether the name evoked few or many different images for that particular object. In the age-of-acquisition task, the subjects were asked to estimate the age at which they thought they had learned each of the names, in its written or its oral form. We altered the scale used by Morrison et al. (1997) from 7 points to 5 points, where $1=$ learned at $0-3$ years and $5=$ learned at age $12+$, with 3 -year age bands in between. For this specific task, 17 words were repeated, to provide a reliability check. The correlation between these repeated ratings was .94 , and the means were not significantly different $[2.68 \mathrm{vs} .2 .56 ; t(16)=0.11]$.

Concerning verbal association measures, we report Ferrand and Alario's (1998) results (when available for the present stimuli). Overall, 263 associations were available out of the 400 stimuli. These free association norms were collected by presenting a large group of French-speaking subjects $(n=89)$ with a written stimulus word and asking them to respond with the first word they think of, as quickly as they can (for details, see Ferrand \& Alario, 1998).

\section{RESULTS AND DISCUSSION}

A summary of the rating data obtained from our sample of French-speaking subjects is presented in Appendix A. To allow for easy reference and data comparison, entries are listed according to the identifying numbers originally assigned to each drawing by Cycowicz et al. (1997). Moreover, a computer file (Excel or ASCII format) with all the data is available on request for research facilities. For each picture, the following information is presented: (1) the most frequent name given in French (with an English translation); (2) two measures of name agreement, the statistic $H$ (taken from Snodgrass \& Vanderwart, 1980) and the percentage of subjects producing the most common name; and (3) the means and standard deviations for image agreement, familiarity, visual complexity, image variability, and age of acquisition. Along with the ratings obtained for French-speaking subjects, Appendix A presents the frequency of the single name (taken from Content et al., 1990), as well as the first verbal associate (obtained by Ferrand \& Alario, 1998). Appendix $B$ lists the alternate names given to each drawing, with an indication of their frequency. A frequency of zero indicates that the single-word name did not occur in the Content et al. corpus. Because the Content et al. corpus does not provide counts for names of more than one word, these unavailable frequencies are indicated by a dash. Failures in the naming task are listed as DKN, DKO, and TOT. All nondominant names given for each concept are listed and accompanied by their frequencies (when available).

Following Snodgrass and Vanderwart (1980), we used a strict criterion for counting different instances of names when computing $H$ values. In many cases, the name given by a subject was similar to but not identical with an established name category. A picture that elicited the same name from every subject in the sample who was able to name it has an $H$ value of .00 . Increasing $H$ values indicate decreasing name agreement and, generally, decreasing percentages of subjects who all gave the same name. According to Snodgrass and Vanderwart,

the $H$ value captures more information about the distribution of names across subjects than does the percentage agreement measure. For example, if two concepts both are given their dominant name by $60 \%$ of the subjects, but one is given a single other name and the second is given four other names, both concepts will have equal percentage agreement scores, but the first will have a lower $H$ value. (p. 184)

Table 1 presents summary statistics for the following indices: $H$ (reflecting name agreement), percentage of subjects producing the modal names, image agreement, familiarity, complexity, variability, age of acquisition, and frequency. Although $H$ and percentage are two measures of name agreement, following Snodgrass and Vanderwart's (1980) arguments, we will use $H$ as the measure of name agreement. The 25th (Q1) and the 75th (Q3) percentiles are shown to facilitate selection of con- 
Table 1

Summary Statistics for All Variables

\begin{tabular}{|c|c|c|c|c|c|c|c|c|}
\hline \multirow[b]{2}{*}{ Statistic } & \multicolumn{2}{|c|}{$\begin{array}{c}\text { Name } \\
\text { Agreement }\end{array}$} & \multirow{2}{*}{$\begin{array}{c}\text { Image } \\
\text { Agreement }\end{array}$} & \multirow[b]{2}{*}{ Familiarity } & \multirow[b]{2}{*}{ Complexity } & \multirow{2}{*}{$\begin{array}{c}\text { Image } \\
\text { Variability }\end{array}$} & \multirow[b]{2}{*}{ A-A } & \multirow[b]{2}{*}{$F$} \\
\hline & $H^{*}$ & $\%$ & & & & & & \\
\hline $\bar{M}$ & 0.36 & 84.63 & 3.44 & 2.72 & 3.09 & 2.76 & 2.56 & 29.82 \\
\hline$S D$ & 0.43 & 20.31 & 0.78 & 1.19 & 0.92 & 0.63 & 0.79 & 78.96 \\
\hline Median & 0.15 & 96 & 3.57 & 2.42 & 3.07 & 2.60 & 2.51 & 7.04 \\
\hline Range & 1.87 & 82 & 3.90 & 3.94 & 4 & 3.50 & 3.65 & 892 \\
\hline Min & 0 & 18 & 1 & 1.03 & 1 & 1.20 & 1.12 & 0 \\
\hline Max & 1.87 & 100 & 4.90 & 4.97 & 5 & 4.70 & 4.77 & 892 \\
\hline Q1 & 0 & 75 & 2.97 & 1.73 & 2.38 & 2.30 & 1.95 & 1.61 \\
\hline Q3 & 0.65 & 100 & 4 & 3.77 & 3.74 & 3.17 & 3.08 & 21.88 \\
\hline IRQ & 0.65 & 25 & 1.03 & 2.04 & 1.36 & 0.87 & 1.13 & 20.27 \\
\hline Skew & 3.33 & 0.19 & 0.72 & 1.98 & 0.97 & 1.90 & 1.02 & 2.74 \\
\hline
\end{tabular}

cepts from the extremes of the distribution. The distribution of $H$ values has a low mean and is positively skewed, reflecting the fact that many concepts show high name agreement.

Table 2 presents summary statistics for the following indices: $H$, image agreement, familiarity, and complexity. This table contains the summary for the French samples of the current study, the Spanish-speaking samples reported by Sanfeliu and Fernández (1996), and the English-speaking samples reported by Snodgrass and Vanderwart (1980). As can be seen from this table, there were small differences for image agreement, familiarity, and complexity. There was a larger difference when the $H$ value was considered. The English-speaking sample had bigger $H$ values than did the French and Spanish ones. It seems to indicate that the French sample and the Spanish sample showed less variability in the number of names applied to objects than did the English-speaking sample.

We performed two correlational analyses on the data. The first one correlated (1) the data provided by Snodgrass and Vanderwart (1980) with the data obtained in the present study (for the 253 drawings common to both studies) for $H$, image agreement, familiarity, and visual complexity and (2) the data provided by Sanfeliu and Fernández (1996) with the data obtained in the present study for the same variables. As is shown in Tables 3 and 4 , there were fairly high and significant correlations for all the variables. Correlations were higher for familiarity and complexity (for both French-English and FrenchSpanish) than for name agreement ( $H$ and \%) and image agreement.

The second correlational analysis concerned the data obtained in the present study for the 400 line drawings taken from Cycowicz et al. (1997). To determine the degree of relationship among our measures and between them and some important measures already available, we computed the interitem correlations among all the attributes presented in Appendix A (following Snodgrass \& Vanderwart, 1980). Table 5 shows the matrix of correlations for all the concepts, with the significant correlation coefficients marked with an asterisk. Because frequency measures (taken from Content et al., 1990) were available for only 355 of the 400 concept names, a separate set of correlations was computed for this subset.

As was expected, the two measures of name agreement $(H$ and $\%)$ show a high negative correlation $(-.952$ in Table 5). The correlations among the other measures col-

Table 2

Summary Statistics for Four Variables: American, Spanish, and French Samples (for Snodgrass and Vanderwart Pictures)

\begin{tabular}{|c|c|c|c|c|c|c|c|c|c|c|c|c|}
\hline \multirow[b]{2}{*}{ Statistic } & \multicolumn{3}{|c|}{ Name Agreement $(H)$} & \multicolumn{3}{|c|}{ Image Agreement } & \multicolumn{3}{|c|}{ Familiarity } & \multicolumn{3}{|c|}{ Complexity } \\
\hline & U.S. & Spain & France & U.S. & Spain & France & U.S. & Spain & France & U.S. & Spain & France \\
\hline$M$ & 0.56 & 0.27 & 0.28 & 3.69 & 3.71 & 3.46 & 3.29 & 3.12 & 3.06 & 2.96 & 2.67 & 3.00 \\
\hline$S D$ & 0.53 & 0.41 & 0.36 & 0.58 & 0.60 & 0.78 & 0.96 & 1.11 & 1.21 & 0.89 & 0.93 & 0.96 \\
\hline Median & 0.42 & 0.12 & 0.15 & 3.72 & 3.84 & 3.60 & 3.32 & 3.06 & 2.92 & 2.93 & 2.52 & 2.95 \\
\hline Range & 2.55 & 2.19 & 1.41 & 2.68 & 3.03 & 3.73 & 3.72 & 3.67 & 3.90 & 3.78 & 3.68 & 4 \\
\hline Min & 0 & 0 & 0 & 2.05 & 1.74 & 1.17 & 1.18 & 1.27 & 1.07 & 1 & 1.05 & 1 \\
\hline $\operatorname{Max}$ & 2.55 & 2.19 & 1.41 & 4.73 & 4.77 & 4.90 & 4.90 & 4.94 & 4.97 & 4.78 & 4.73 & 5 \\
\hline Q1 & 0.12 & 0.04 & 0 & 3.27 & 3.29 & 2.93 & 2.49 & 2.16 & 1.97 & 2.28 & 1.98 & 2.28 \\
\hline Q3 & 0.87 & 0.28 & 0.47 & 4.15 & 4.16 & 4.05 & 4.09 & 4.08 & 4.17 & 3.59 & 3.39 & 3.71 \\
\hline Skew & 1.5 & 2.39 & 2.13 & 0.96 & -0.71 & 0.67 & 0.93 & 0.01 & 1.32 & 1.02 & 0.28 & 1.13 \\
\hline Valid cases & 260 & 254 & 256 & 260 & 245 & 256 & 260 & 254 & 256 & 260 & 254 & 256 \\
\hline
\end{tabular}

Note-Q1, 25th percentile; Q3, 75th percentile; skew, $\left(\mathrm{Q} 3-\right.$ Median)/(Median - Q1); $>1$ is positively skewed. ${ }^{*}$ Increasing $H$ values indicate decreasing name agreement. 
Table 3

Significant Correlations Among the Measured Variables in the French and American Samples (for Snodgrass and Vanderwart Pictures)

\begin{tabular}{lccccc}
\hline & \multicolumn{5}{c}{ American Sample } \\
\cline { 2 - 6 } \multicolumn{1}{c}{ French Sample } & NA $(H)$ & $\%$ & IA & Fam & Comp \\
\hline Name agreement $(H)$ & .428 & .429 & & & \\
Name agreement $(\%)$ & & .498 & & \\
Image agreement & & & .913 & \\
Familiarity & & & & .945 \\
Visual complexity & & & & &
\end{tabular}

Note-NA, name agreement; IA, image agreement; Fam, familiarity; Comp, visual complexity. All listed correlation coefficients for the present study and the Snodgrass and Vanderwart (1980) study are significant at $p<.01$.

Table 4

Significant Correlations Among the Measured Variables in the French and Spanish Samples (for Snodgrass and Vanderwart Pictures)

\begin{tabular}{|c|c|c|c|c|c|}
\hline \multirow[b]{2}{*}{ French Sample } & \multicolumn{5}{|c|}{ Spanish Sample (Sanfeliu \& Fernández, 1996) } \\
\hline & NA $(H)$ & $\%$ & IA & Fam & Comp \\
\hline Name agreement $(H)$ & .313 & & & & \\
\hline Name agreement (\%) & & .506 & & & \\
\hline Image agreement & & & .524 & & \\
\hline Familiarity & & & & .778 & \\
\hline Visual complexity & & & & & .727 \\
\hline
\end{tabular}

lected in the present study (familiarity, complexity, image agreement, image variability, and age of acquisition) are all relatively small in magnitude, suggesting that the measures represent independent attributes. Overall, these correlations are similar to the ones obtained by Snodgrass and Vanderwart (1980) and by Cycowicz et al. (1997).

Familiarity is negatively correlated with age of acquisition (-.578), suggesting that names of concepts that are familiar tend to be learned at an early age. As is shown in Table 5, familiarity is positively correlated with frequency $(.360)$. The correlation between age of acquisition and frequency, although modest $(-.367)$, is also significant. Of the correlations among our own measures, name agreement and image agreement are negatively correlated $(-.343)$, suggesting that concepts that have many names also evoke many different images. The correlation between age of acquisition and name agreement (.453) suggests that, for concepts acquired at an early age, the level of agreement is high. The fact that French speakers' name agreement correlates less with word frequency than with age of acquisition is similar to the finding that, for American and English speakers, age of acquisition has a greater influence on picture naming than do other variables (Caroll \& White, 1973; Ellis \& Morrison, 1998). The correlations between image variability and both age of acquisition $(-.654)$ and familiarity (.616) suggest that concepts that are learned early evoke more images than do concepts that are learned late. Finally, visually complex pictures tend to be rated as unfamiliar (significant correlation of - .391).

Table 5

Correlations Among the Measured Variables in a French Sample for Cycowicz, Friedman, Rothstein, and Snodgrass (1997) Pictures

\begin{tabular}{lcccccccc}
\hline \multicolumn{1}{c}{ Variable } & NA & $\%$ & IA & Fam & Comp & I-Var & A-A & Freq $\dagger$ \\
\hline Name agreement $(H)$ & 1.000 & & & & & & & \\
Name agreement (\%) & $-.952^{*}$ & 1.000 & & & & & & \\
Image agreement & $-.343^{*}$ & $.370^{*}$ & 1.000 & & & & & \\
Familiarity & $-.183^{*}$ & $.215^{*}$ & -.035 & 1.000 & & & & \\
Visual complexity & .081 & -.081 & -.009 & $-.391^{*}$ & 1.000 & & & \\
Image variability & $-.255^{*}$ & $.317^{*}$ & -.097 & $.616^{*}$ & $-.210^{*}$ & 1.000 & & \\
Age of acquisition & $.453^{*}$ & $-.524^{*}$ & $-.140^{*}$ & $-.578^{*}$ & $.214^{*}$ & $-.654^{*}$ & 1.000 & \\
Frequency $\dagger$ & $-.140^{*}$ & $.151^{*}$ & -.005 & $.360^{*}$ & $-.136^{*}$ & $.340^{*}$ & $-.367^{*}$ & 1.000 \\
\hline
\end{tabular}

Note-NA, name agreement; IA, image agreement; Fam, familiarity; Comp, visual complexity; I-Var, image variability; A-A, age of acquisition; Freq, frequency (taken from Content, Mousty, \& Radeau, 1990). ${ }^{*}$ Correlation coefficients significant at $p<.01$. † Concerning the frequency variable, correlations among all measured variables were obtained for a sample of 355 concepts only, for which frequency values were available. 


\section{CONCLUSION}

The main goal of the present research was to collect normative data for pictorial stimuli that could be used in research with French-speaking samples (see Sanfeliu \& Fernández, 1996, for the same approach in Spanish). Descriptive ratings for a number of picture attributes of the drawings previously presented by Cycowicz et al. (1997) and by Snodgrass and Vanderwart (1980) with American English-speaking subjects are now available for Frenchspeaking subjects. We believe that these normative data will be particularly useful for French researchers interested in memory, language, and other cognitive processes.

\section{REFERENCES}

Attneave, F. (1957). Physical determinants of the judged complexity of shapes. Journal of Experimental Psychology, 53, 221-227.

Barry, C., Morrison, C. M., \& Ellis, A. W. (1997). Naming the Snodgrass and Vanderwart pictures: Effects of age of acquisition, frequency, and name agreement. Quarterly Journal of Experimental Psychology, 50A, 560-585.

Berman, S., Friedman, D., Hamberger, M., \& Snodgrass, J. G. (1989). Developmental picture norms: Relationships between name agreement, familiarity, and visual complexity for child and adult ratings of two sets of line drawings. Behavior Research Methods, Instruments, \& Computers, 21, 371-382.

BIEDERMAN, I. (1987). Recognition-by-components: A theory of human image understanding. Psychological Review, 94, 115-145.

CAroll, J. B., \& WhITE, M. N. (1973). Age-of-acquisition norms for 220 picturable nouns. Journal of Verbal Learning \& Verbal Behavior, 12, 563-576.

Content, A., Mousty, P., \& Radeau, M. (1990). BRUleX. Une base de données lexicales informatisée pour le français écrit et parlé. $L^{\prime} A n$ née Psychologique, 90, 551-566.

Cycowicz, Y. M., Friedman, D., Rothstein, M., \& Snodgrass, J. G. (1997). Picture naming by young children: Norms for name agreement, familiarity, and visual complexity. Journal of Experimental Child Psychology, 65, 171-237.

Des mots en images (1988). Paris: Nathan.

Ellis, A. W., \& MoRrISON, C. M. (1998). Real age-of-acquisition ef fects in lexical retrieval. Journal of Experimental Psychology: Learning, Memory, \& Cognition, 24, 515-523.

FEENAN, K., \& SnOdGrass, J. G. (1990). The effect of context on discrimination and bias in recognition memory for pictures and words. Memory \& Cognition, 18, 515-527.

Ferrand, L., \& Alario, F.-X. (1998). French word association norms for 366 names of objects. L'Année Psychologique, 98, 659-709.

Ferrand, L., Grainger, J., \& Segui, J. (1994). A study of masked form priming in picture and word naming. Memory \& Cognition, 22, 431-441.

Ferrand, L., Humphreys, G. W., \& Segui, J. (1998). Masked repetition and phonological priming in picture naming. Perception \& Psychophysics, 60, 263-274.

Ferrand, L., \& Segui, J. (1998). The syllable's role in speech production: Are syllables chunks, schemas, or both? Psychonomic Bulletin \& Review, 5, 253-258.

Ferrand, L., Segui, J., \& Grainger, J. (1996). Masked priming of word and picture naming: The role of syllabic units. Journal of Memory \& Language, 36, 708-723.

Feyereisen, P., VAN DER Borght, F., \& SERON, X. (1988). The operativity effect in naming: A re-analysis. Neuropsychologia, 26, 401-415.

GERNSBACHER, M. A. (1984). Resolving 20 years of inconsistent interactions between lexical familiarity and orthography, concreteness, and polysemy. Journal of Experimental Psychology: General, 113, 256-281.
Hirshman, E., Snodgrass, J. G., Mindes, J., \& Feenan, K. (1990). Conceptual priming in fragment completion. Journal of Experimental Psychology: Learning, Memory, \& Cognition, 16, 634-647.

Humphreys, G. W., LAmote, C., \& Lloyd-Jones, T. J. (1995). An interactive activation approach to object processing: Effects of structural similarity, name frequency and task in normality and pathology. Memory, 3, 535-586.

L'imagier du Père Castor (1991). Paris: Flammarion.

Johnson, C. J., Paivio, A., \& Clark, J. M. (1996). Cognitive components of picture naming. Psychological Bulletin, 120, 113-139.

KROLL, J. F., \& POTTER, M. C. (1984). Recognizing words, pictures, and concepts: A comparison of lexical, object, and reality decisions. Journal of Verbal Learning \& Verbal Behavior, 23, 39-66.

LACHMAN, R. (1973). Uncertainty effects on time to access the internal lexicon. Journal of Experimental Psychology, 99, 199-208.

Lachman, R., Shaffer, J. P., \& HennRikus, D. (1974). Language and cognition: Effects of stimulus codability, name-word frequency, and age of acquisition on lexical reaction time. Journal of Verbal Learning \& Verbal Behavior, 13, 613-625.

MARTEIN, R. (1995). Norms for name and concept agreement, familiarity, visual complexity and image agreement on a set of 216 pictures. Psychologica Belgica, 35, 205-225.

Morrison, C. M., Chappell, T. D., \& Ellis, A. W. (1997). Age of acquisition norms for a large set of object names and their relation to adult estimates and other variables. Quarterly Journal of Experimental Psychology, 50A, 528-559.

Morrison, C. M., Ellis, A. W., \& Quinlan, P. T. (1992). Age of acquisition, not word frequency, affects object naming, not object recognition. Memory \& Cognition, 20, 705-714.

OldFIELD, R. C., \& WingFiELD, A. (1965). Response latencies in naming objects. Quarterly Journal of Experimental Psychology, 17, 273281.

Paivio, A., Clark, J. M., Digdon, N., \& Bons, T. (1989). Referential processing: Reciprocity and correlates of naming and imaging. Memory \& Cognition, 17, 163-174.

SAnfeliu, M. C., \& Fernández, A. (1996). A set of 254 SnodgrassVanderwart pictures standardized for Spanish: Norms for name agreement, image agreement, familiarity, and visual complexity. Behavior Research Methods, Instruments, \& Computers, 28, 537-555.

SnOdgrass, J. G., \& CoRwiN, J. (1988). Perceptual identification thresholds for 150 fragmented pictures from the Snodgrass and Vanderwart picture set. Perceptual \& Motor Skills, 67, 3-36.

Snodgrass, J. G., \& Feenan, K. (1990). Priming effects in picture fragment completion: Support for the perceptual closure hypothesis. Journal of Experimental Psychology: General, 119, 276-298.

Snodgrass, J. G., Levy-Berger, G., \& Haydon, M. (1985). Human experimental psychology. New York: Oxford University Press.

Snodgrass, J. G., \& Poster, M. (1992). Visual-word recognition thresholds for screen-fragmented names of the Snodgrass and Vanderwart pictures. Behavior Research Methods, Instruments, \& Computers, 24, 1-15.

Snodgrass, J. G., Smith, B., Feenan, K., \& Corwin, J. (1987). Fragmenting pictures on the Apple Macintosh computer for experimental and clinical applications. Behavior Research Methods, Instruments, \& Computers, 19, 270-274.

SNODGRaSS, J. G., \& SuRPRENANT, A. (1989). Effect of retention interval on implicit and explicit memory for pictures. Bulletin of the Psychonomic Society, 27, 395-398.

SNODGRass, J. G., \& VANDERWART, M. (1980). A standardized set of 260 pictures: Norms for name agreement, image agreement, familiarity, and visual complexity. Journal of Experimental Psychology: Human Learning \& Memory, 6, 174-215.

SNodgrass, J. G., \& YudiTsKY, T. (1996). Naming times for the Snodgrass and Vanderwart pictures. Behavior Research Methods, Instruments, \& Computers, 28, 516-536.

VitKovitCH, M., \& TYRrELL, L. (1995). Sources of disagreement in object naming. Quarterly Journal of Experimental Psychology, 48A, 822-848. 
รี ญ่

品

岁它

寻

要

告

$\stackrel{\Xi}{\Xi}$

寻

후응

吕 胥

늘

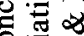

$8<$

웜

몽 훙

它

焉焉

콩

ष

导

$\Xi$ 标

홍

里

豆 豆

导

옹

छ

बิ

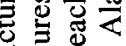

要

迅 苛

4

ปั

월

$\rightarrow \vec{F}$.

政过

造㐫。

这

을

$\stackrel{\infty}{2}$

웡

氙总

容宁

马.

E $:$. n

敢吾

क

을

동층ㅎㅇ

要

造递

象冨

on

$\Xi \Xi$

응 흘

옹 沓票

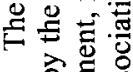

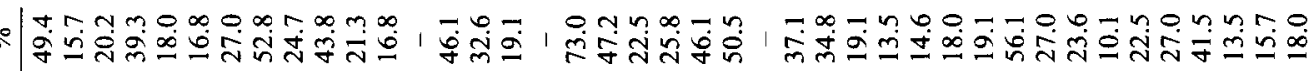

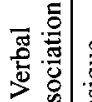

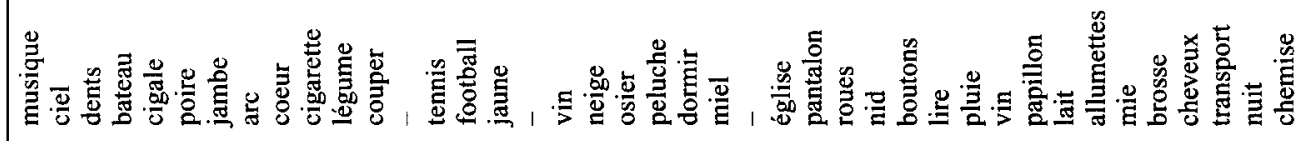

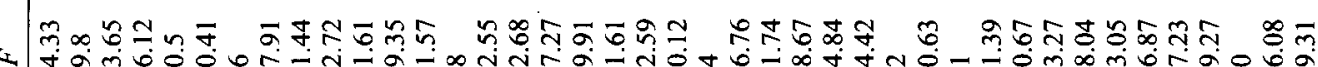

山 भुष

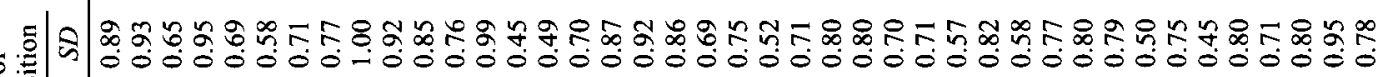
击

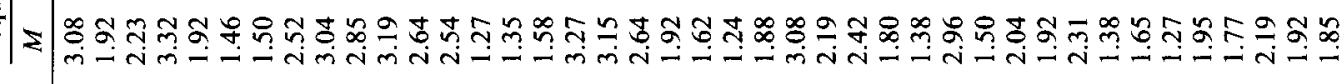

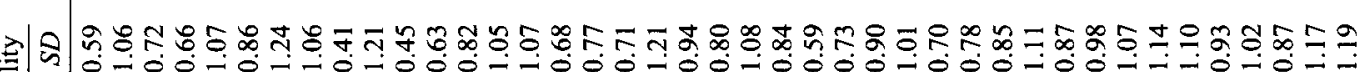

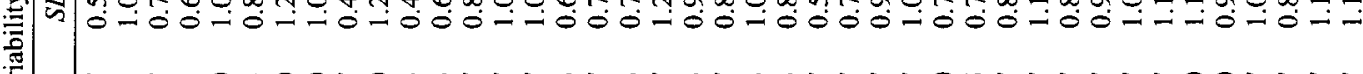

$>$ ₹

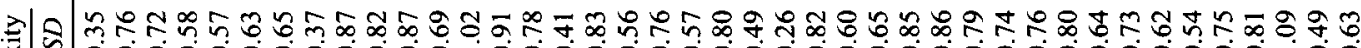
药 $000000000000-0000000000000000000000000-00$

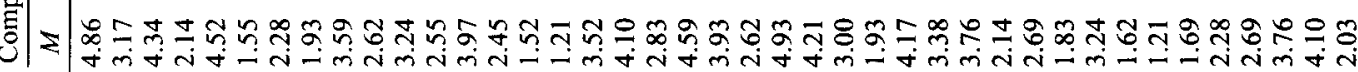

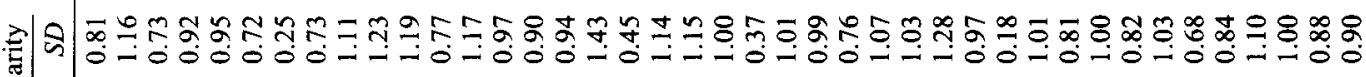

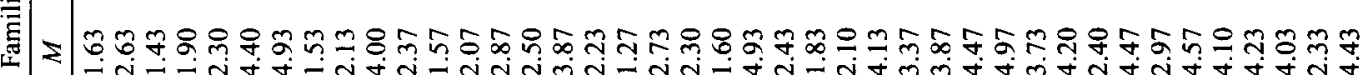

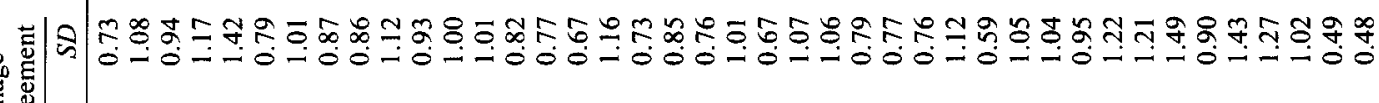

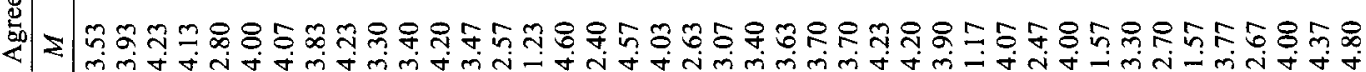

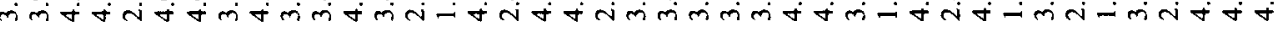

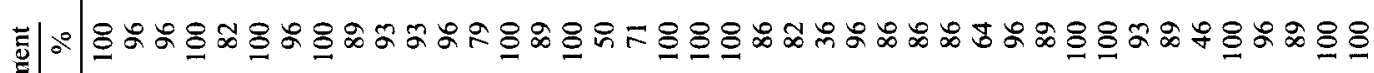
ㅇำ

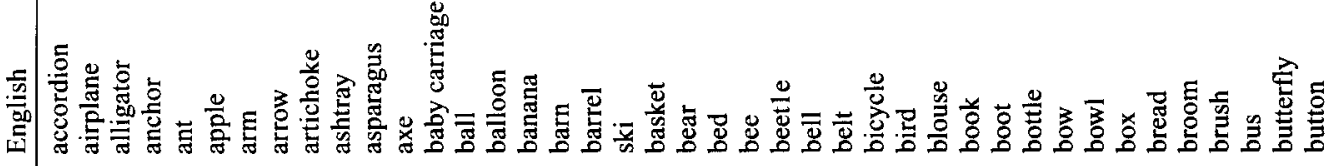

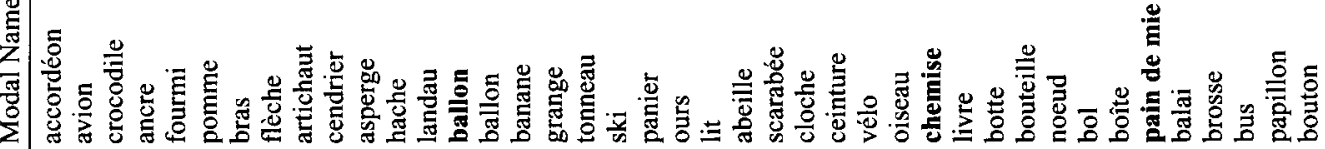




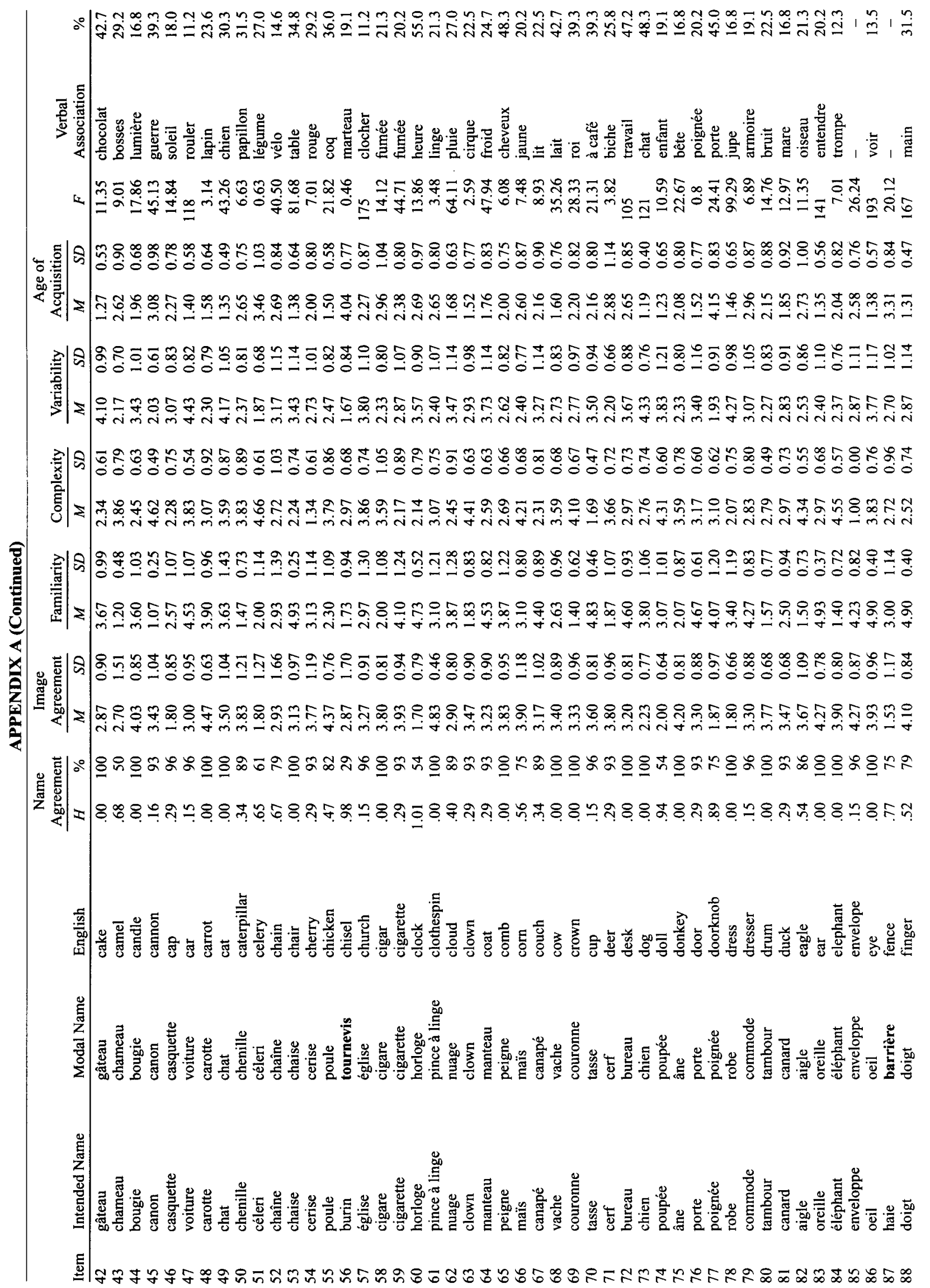




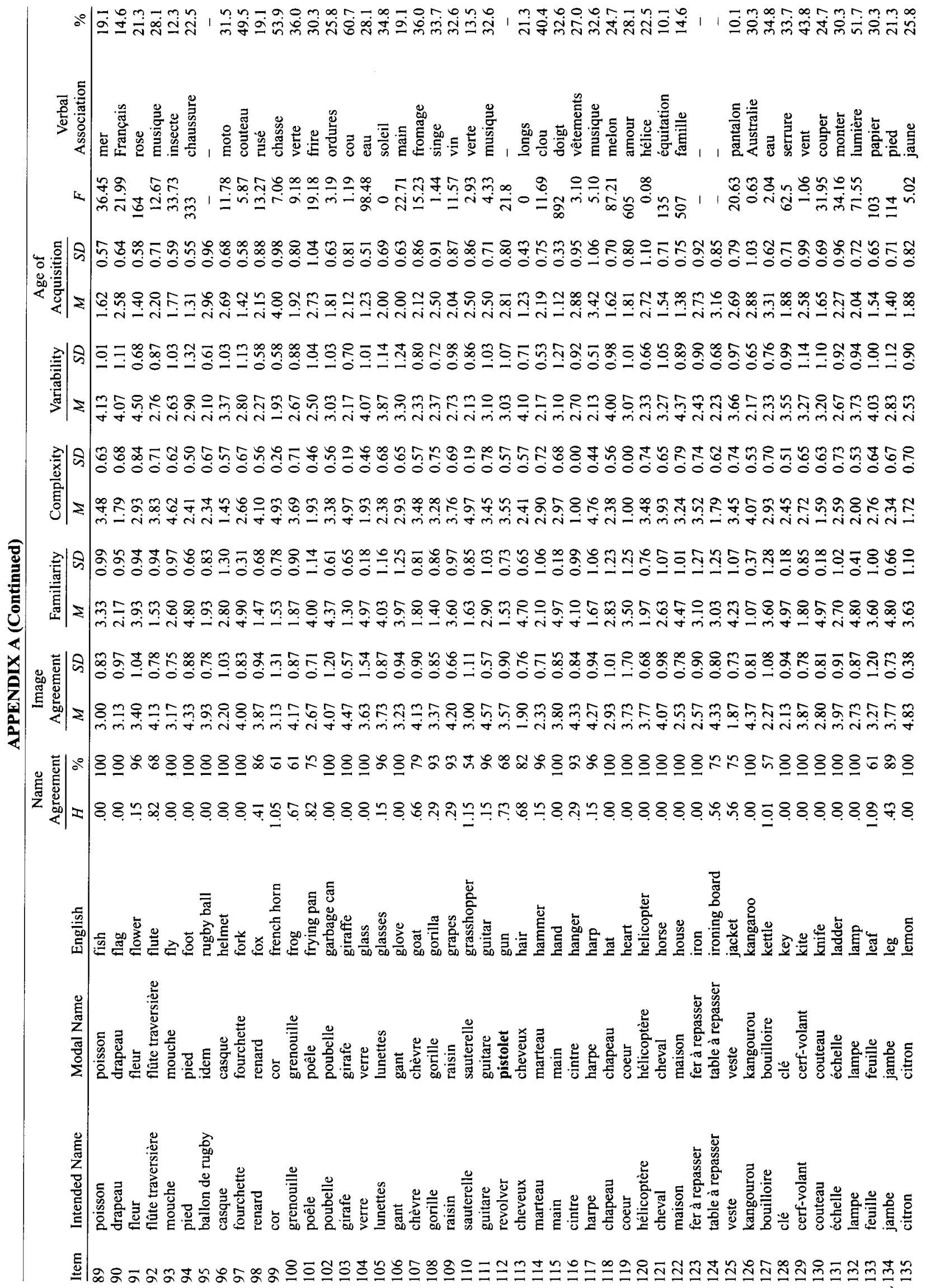


ஓ|-

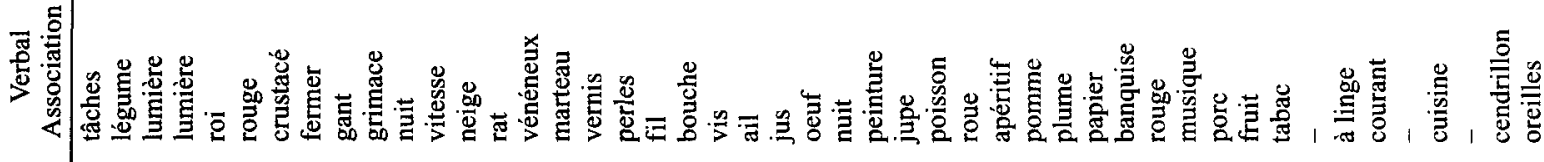

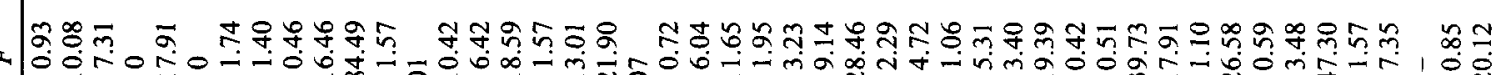

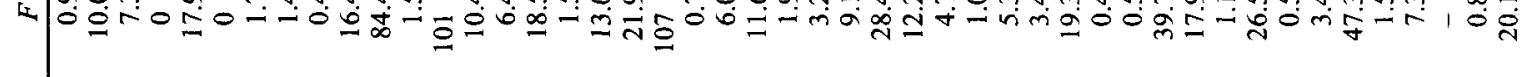

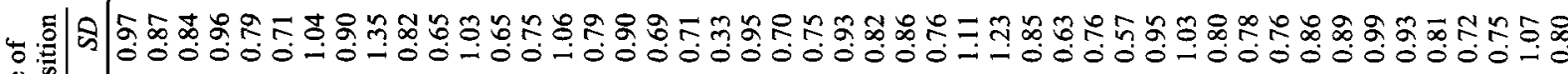
- 00-000000000000- -00000-0000000000-0

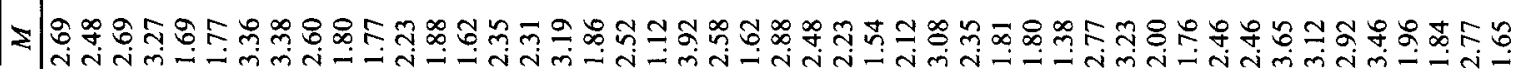

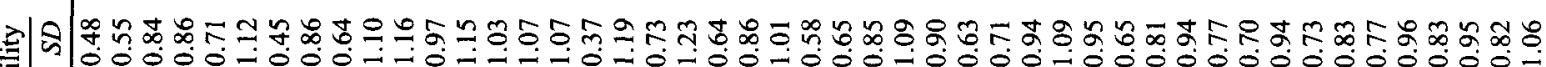
宩 $00000-000-10-1-0-0-00-000-0000-00000000000000-$

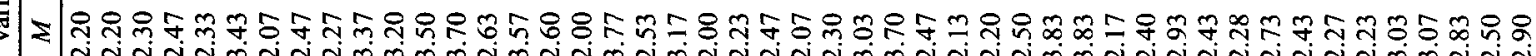
은 年 常

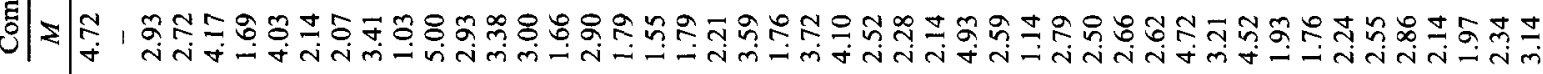

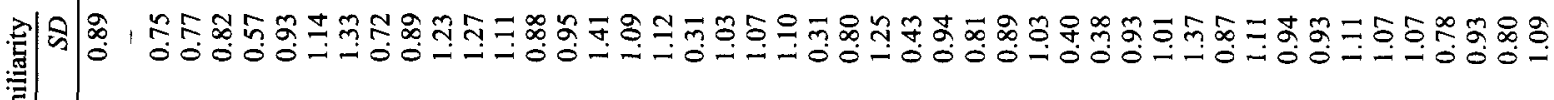

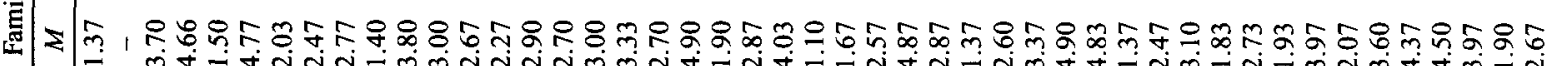

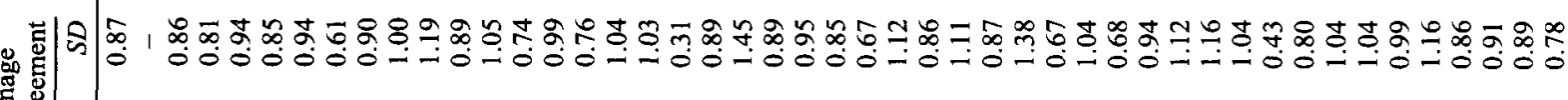

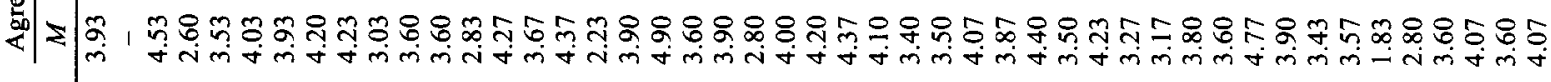

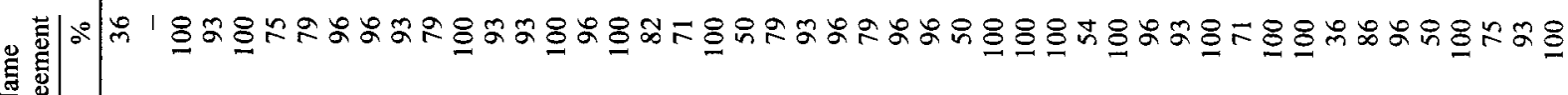

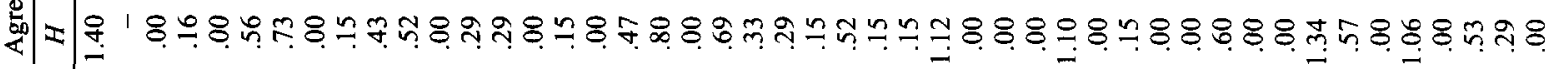

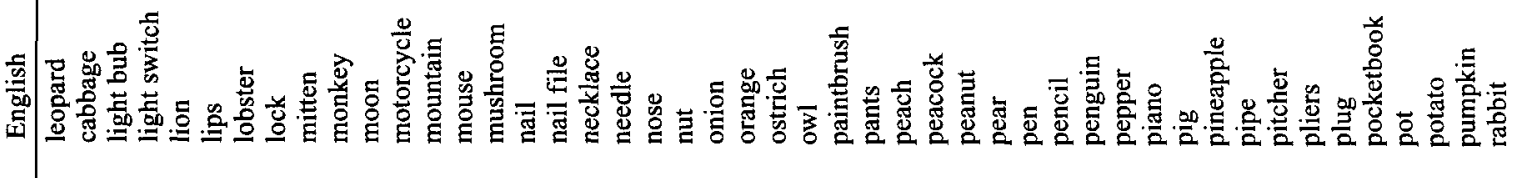

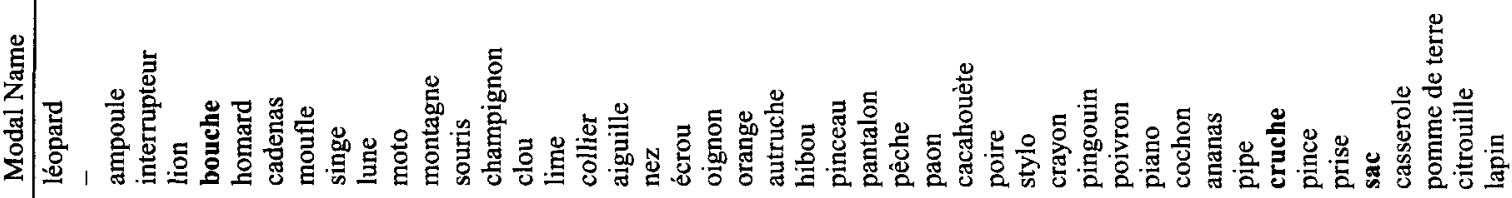




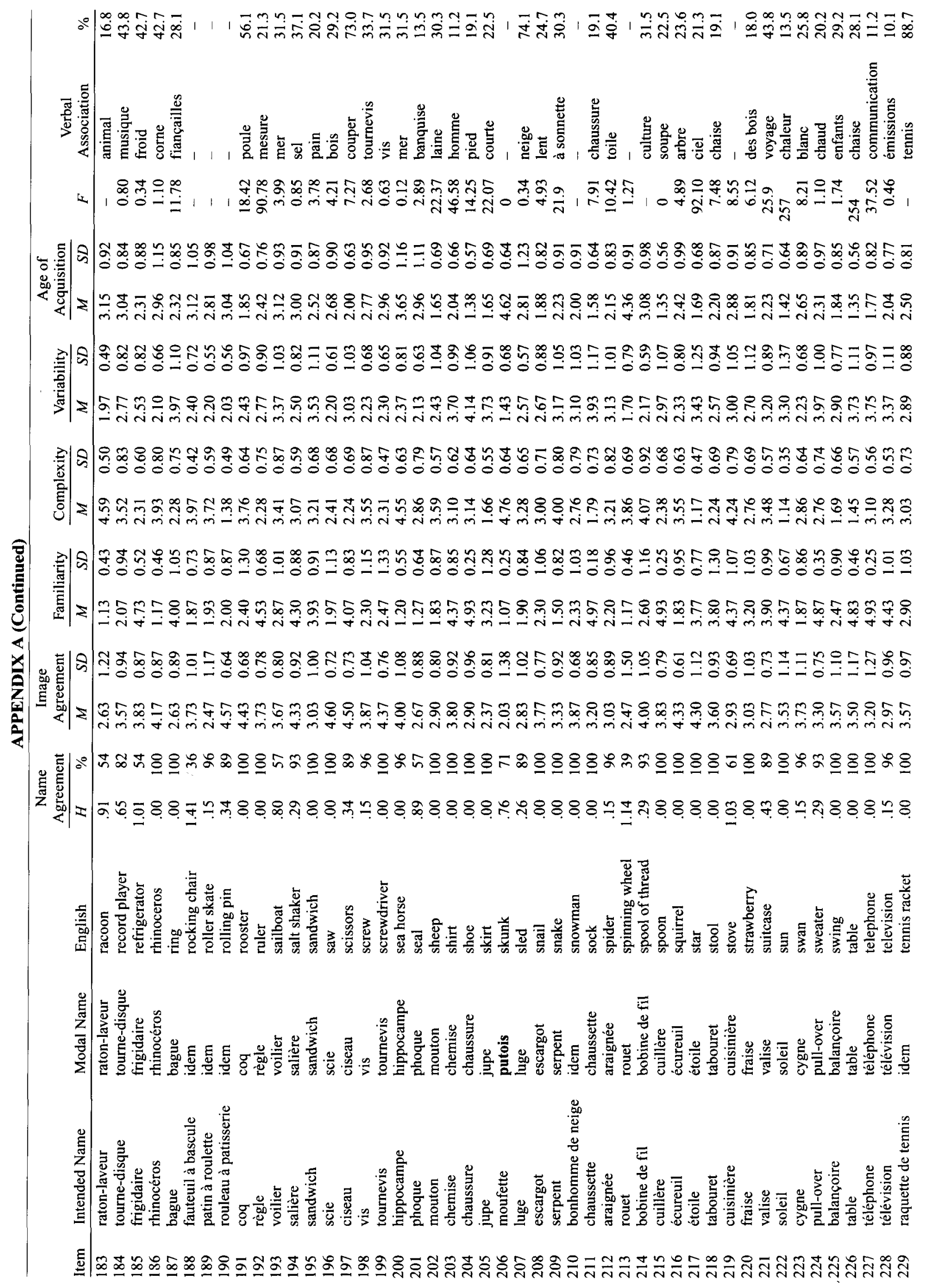




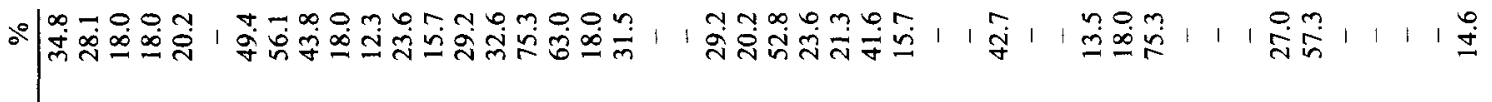

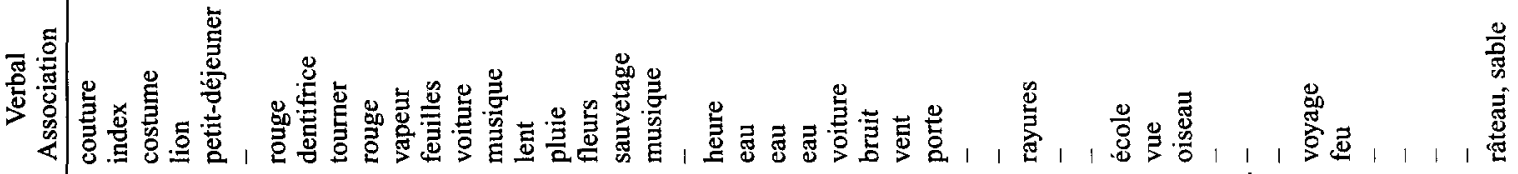
4

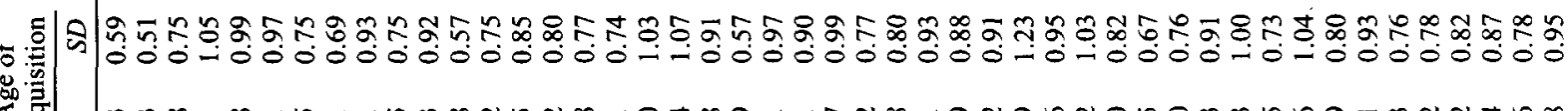
\&

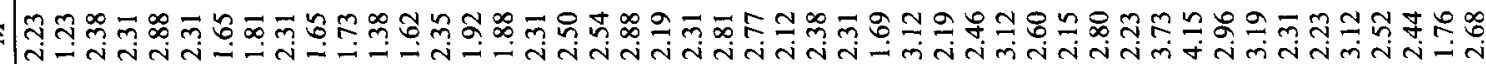

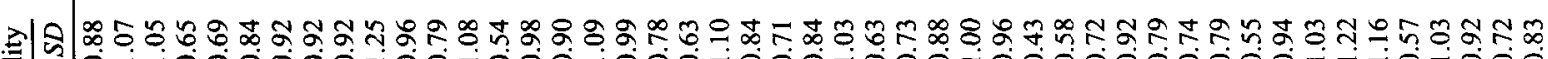
| $0-000000-00-000-000-000-000-0000000000-10-000$

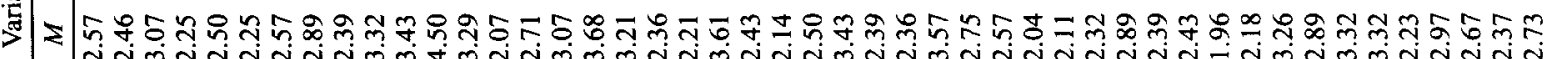

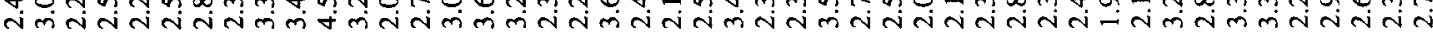

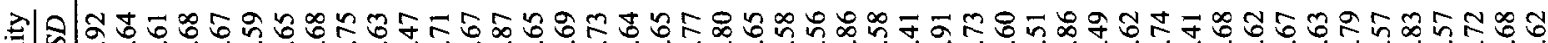
बी 00000000000000000000000000000000000000000000000

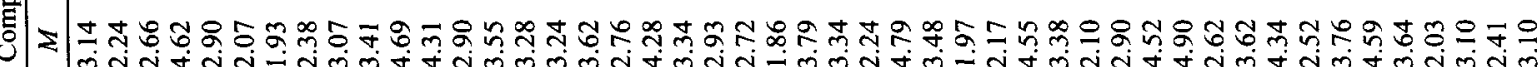

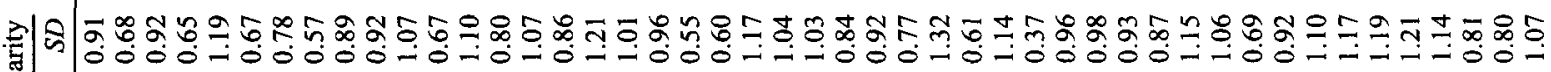

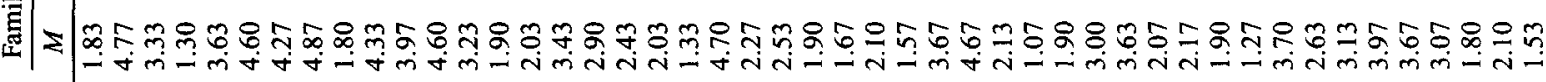

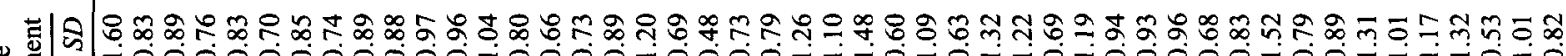
-00000000000-0000-0000-10-0-00-00000-00-1-10-0

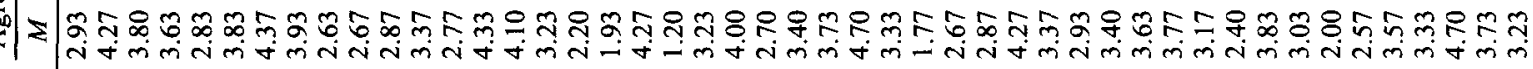

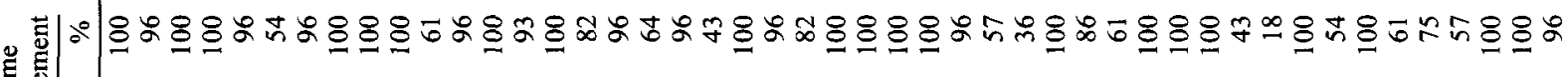

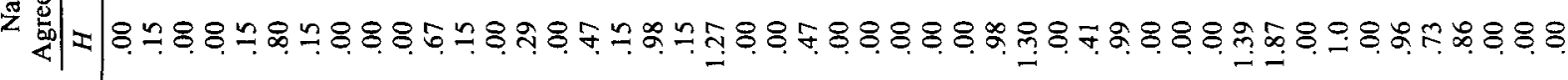

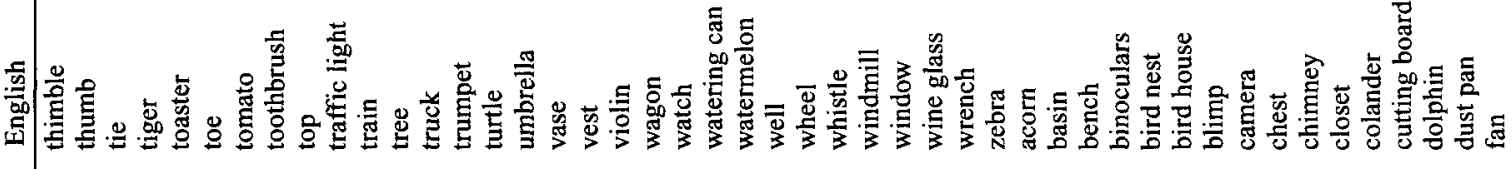

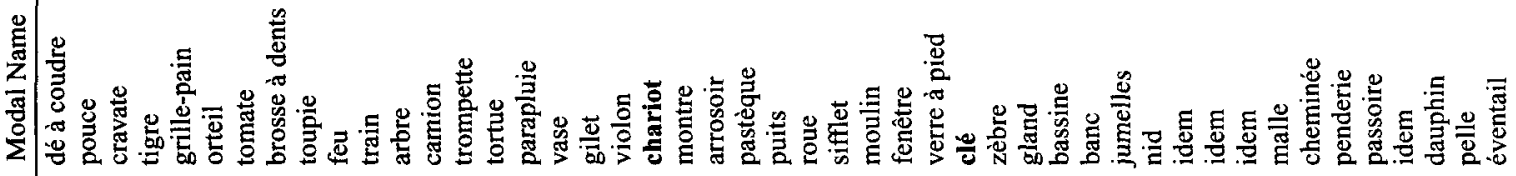

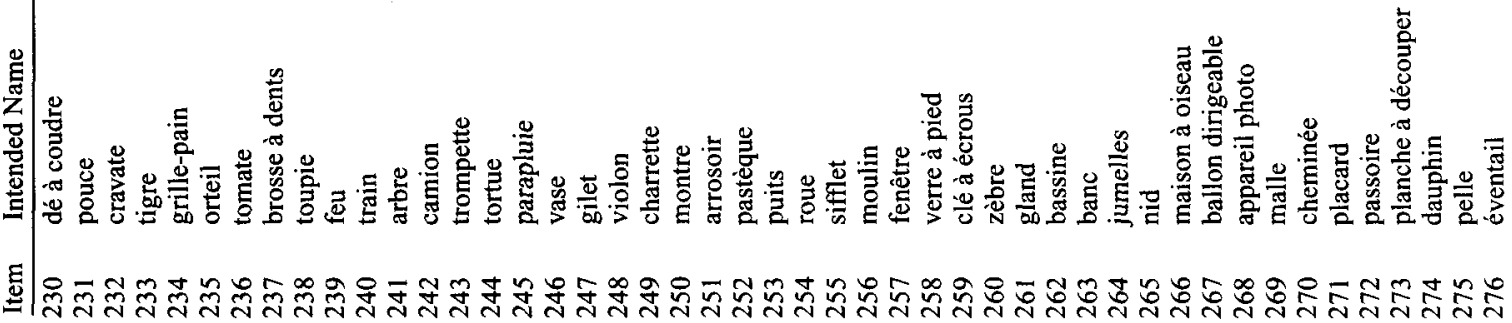




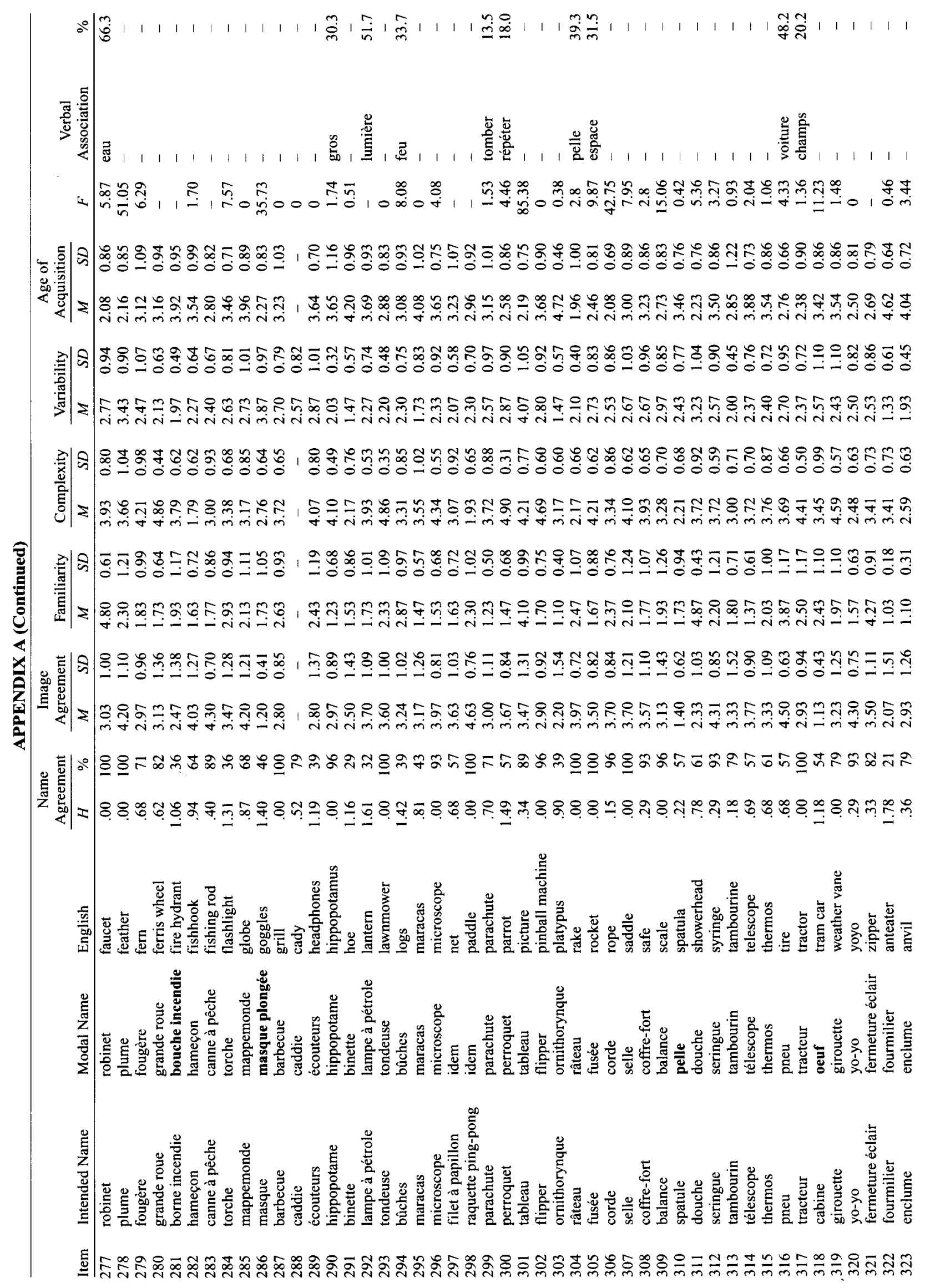




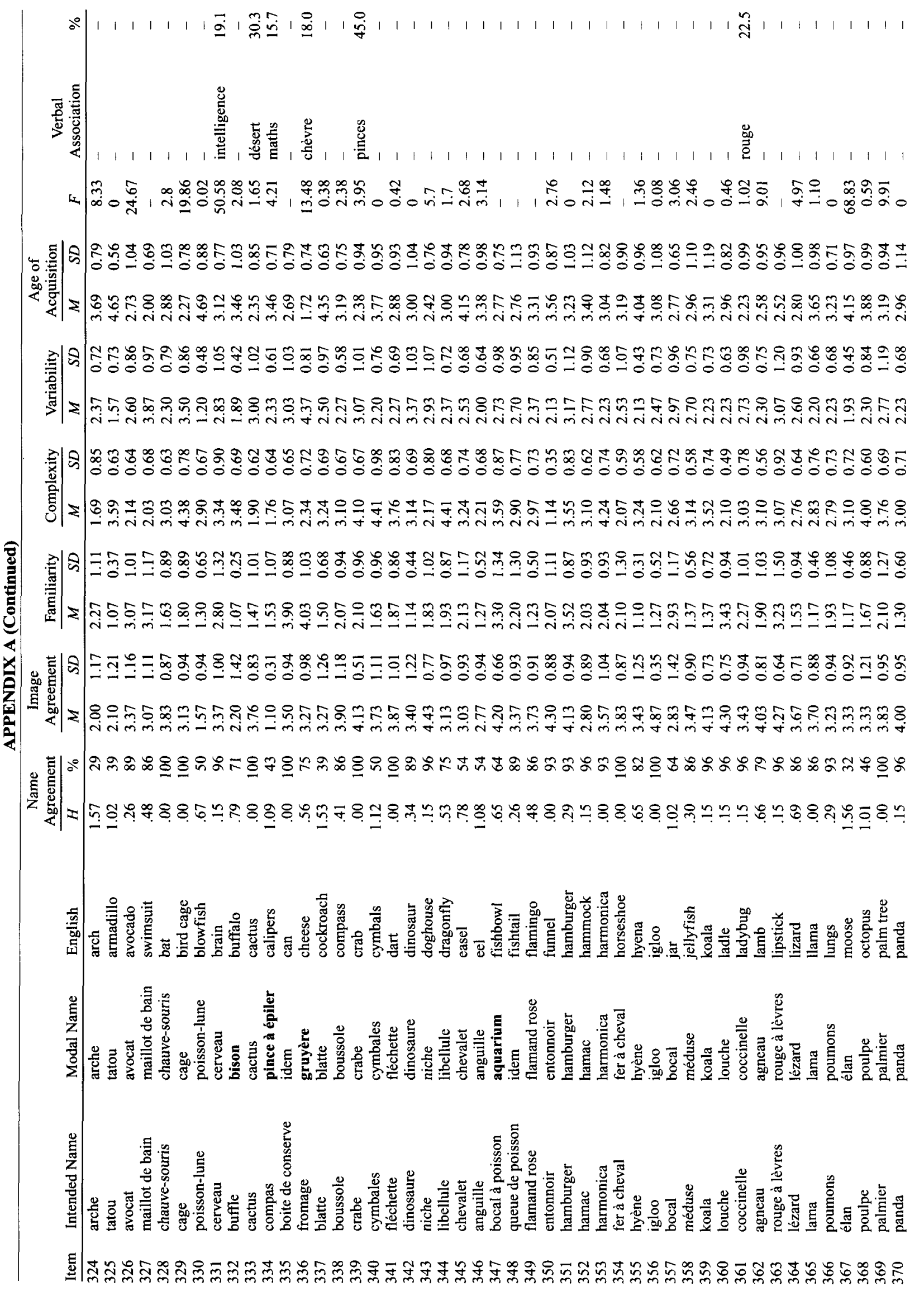




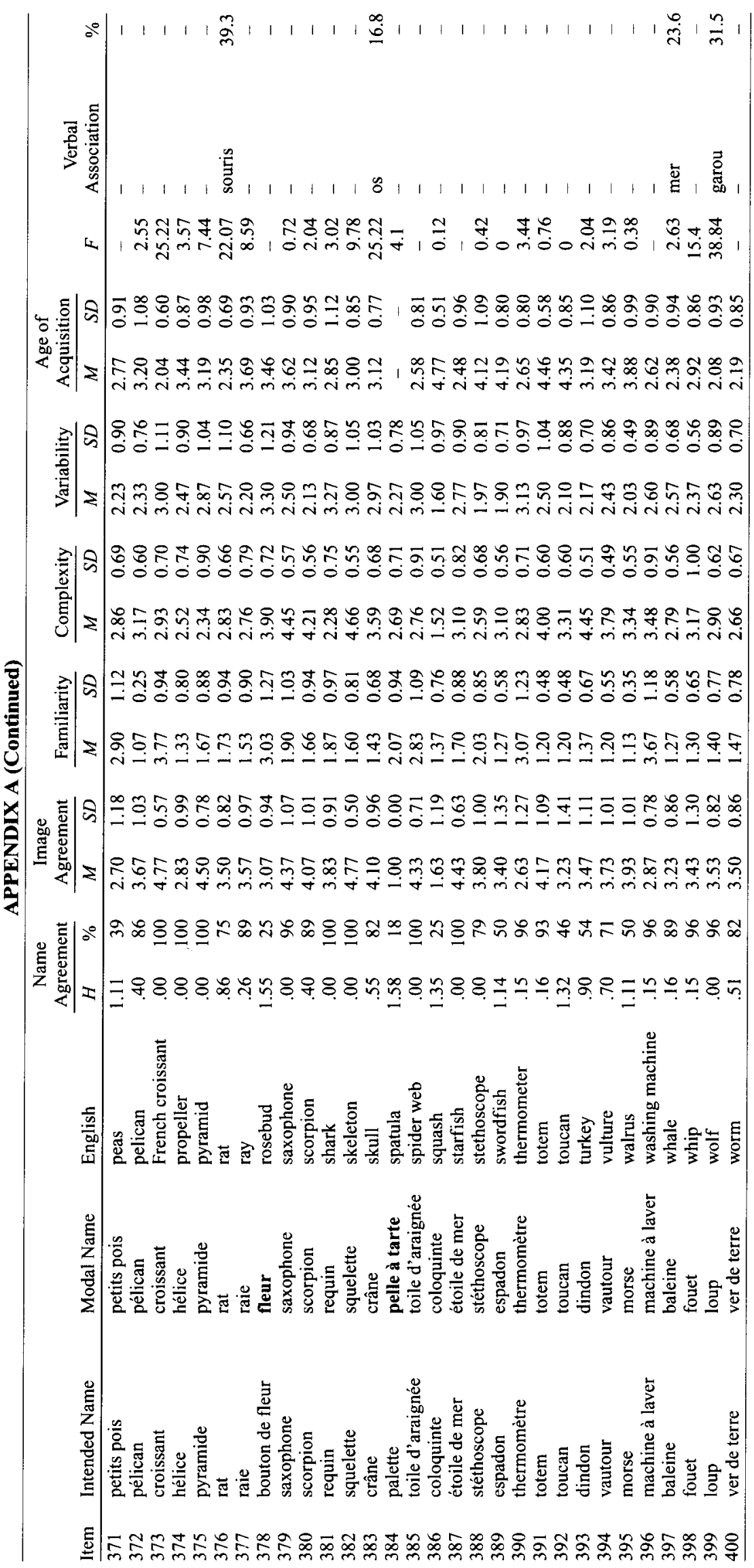




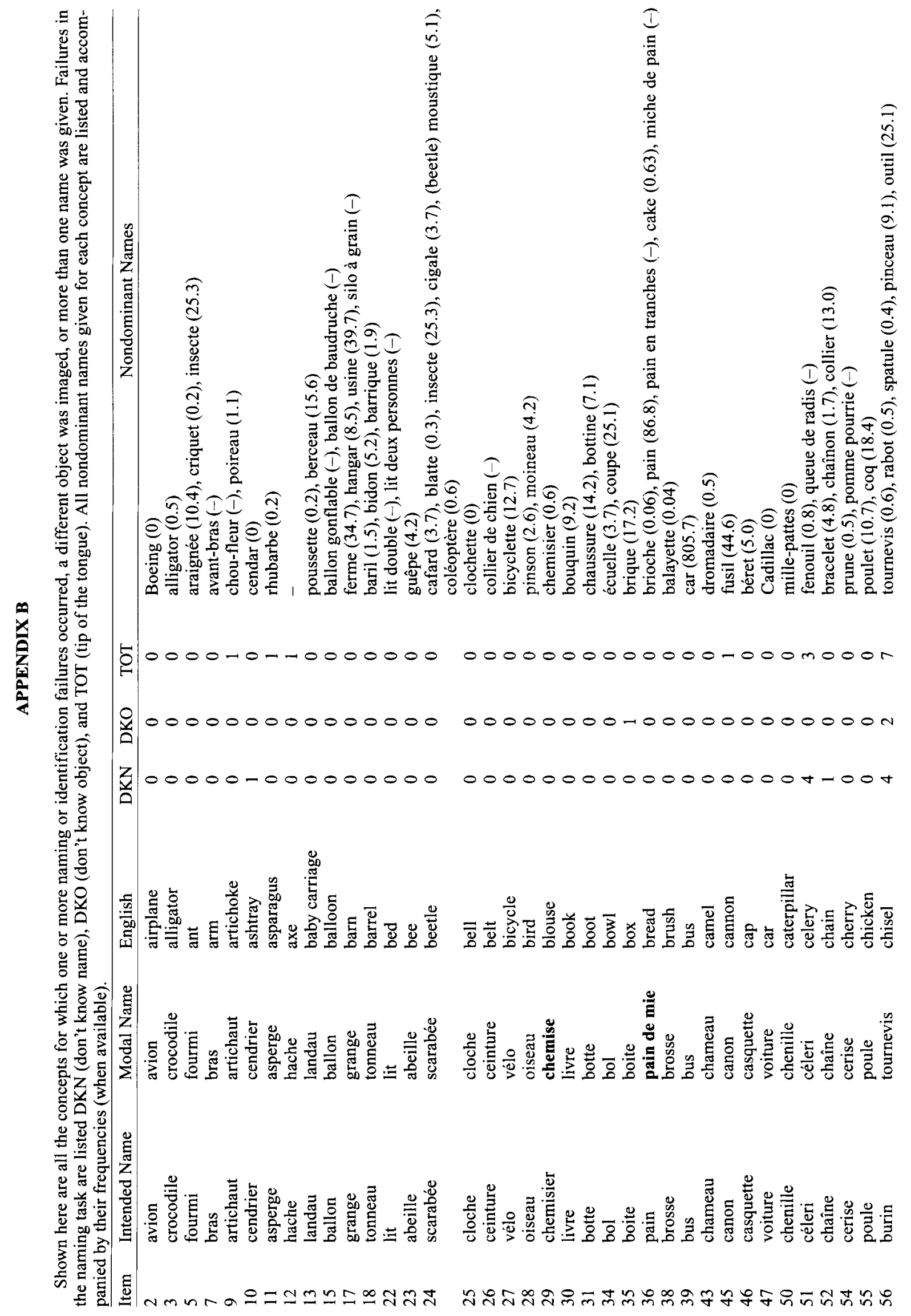




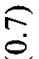<smiles>C=CC(=C)C</smiles>

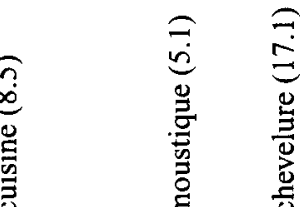

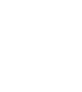

กิ

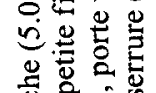

$0000000000000000000000 N 000000000000000-00$

范

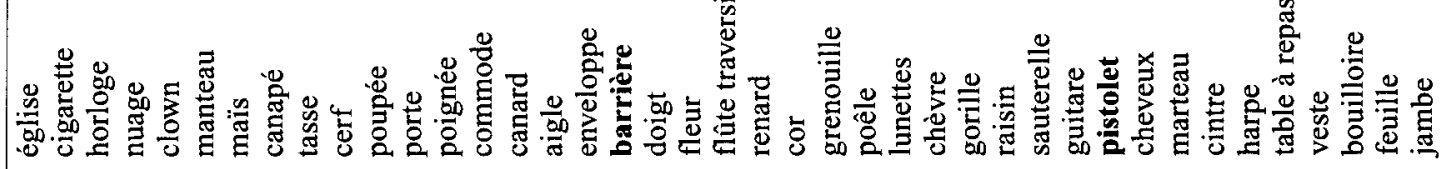




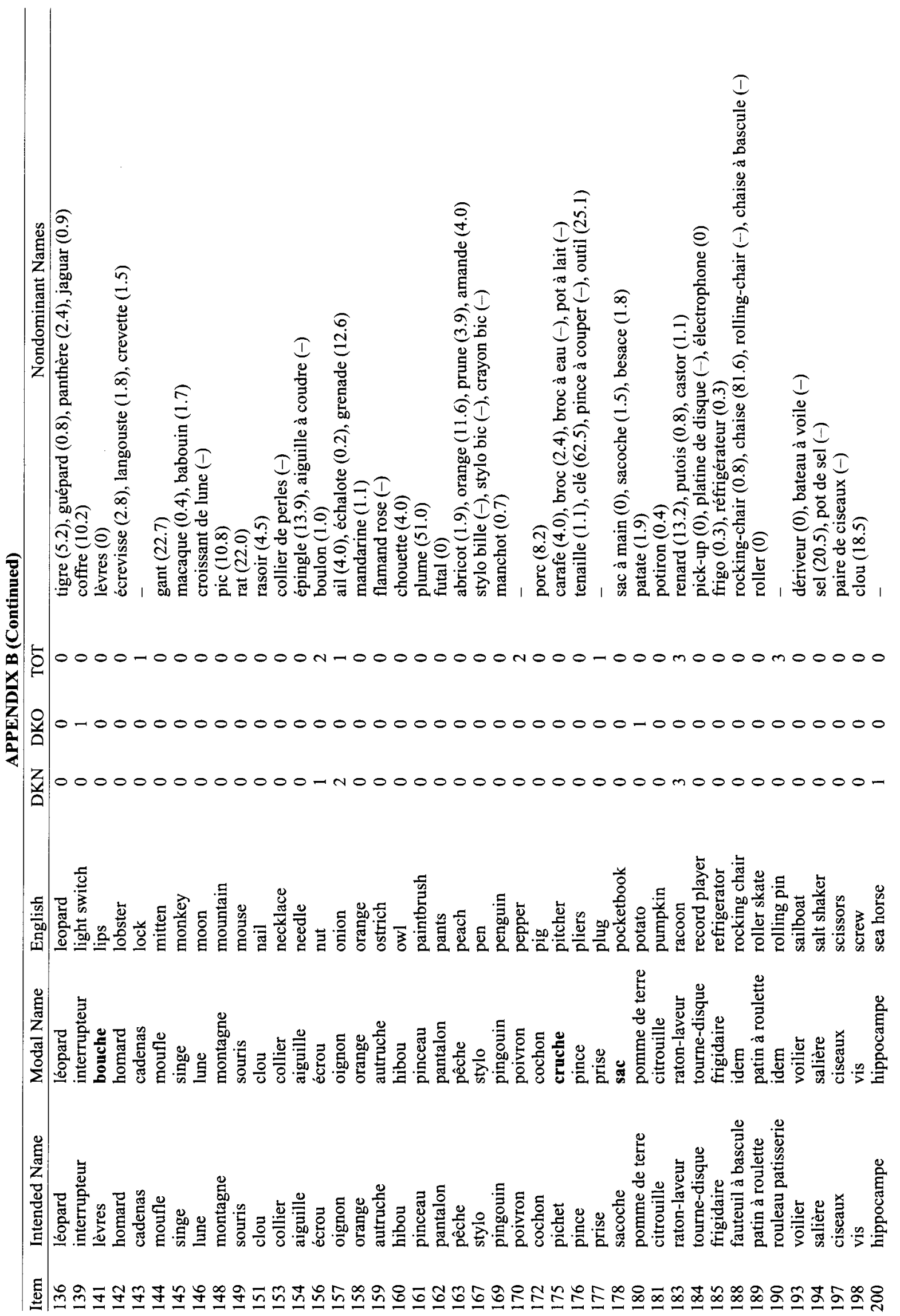




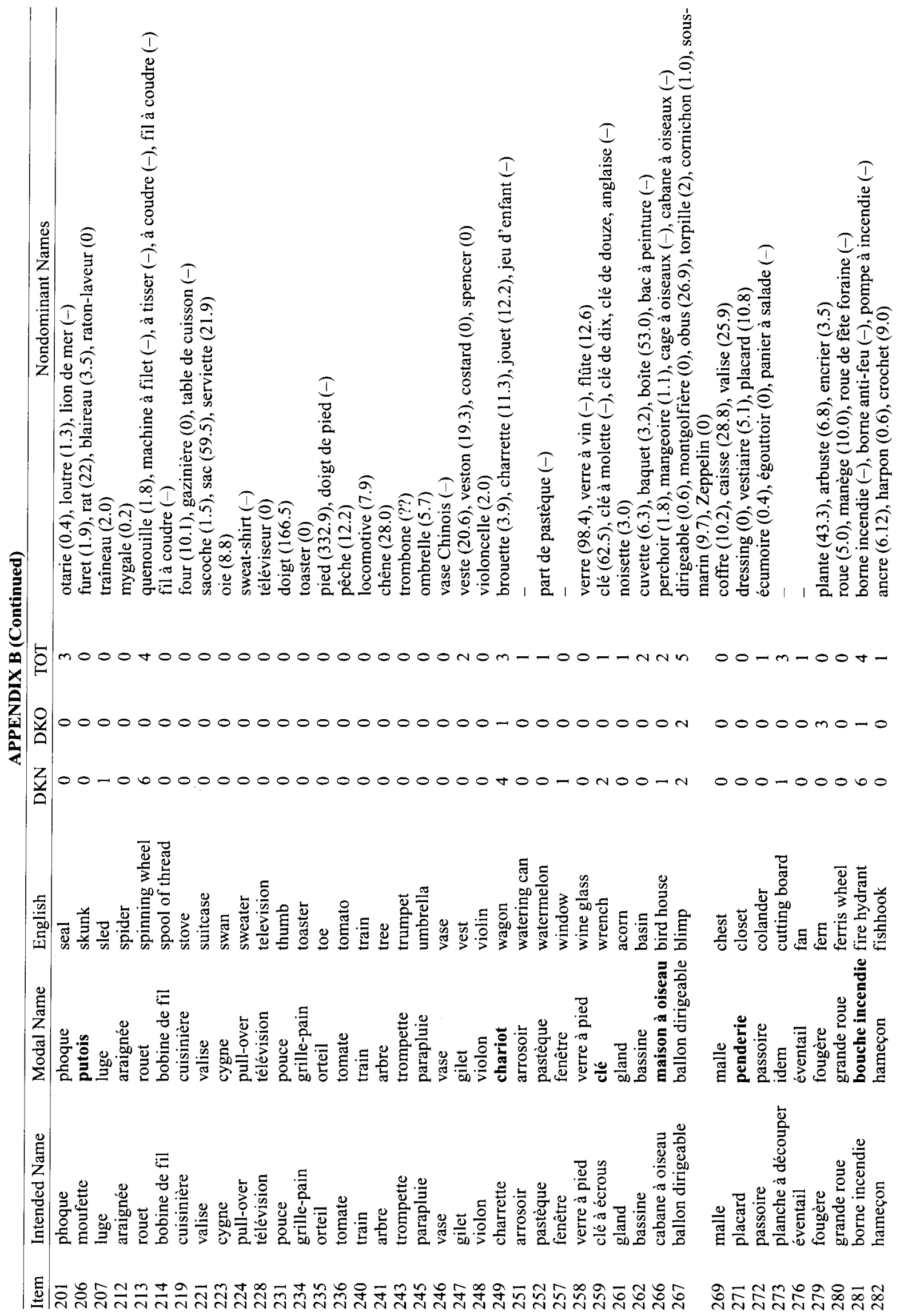




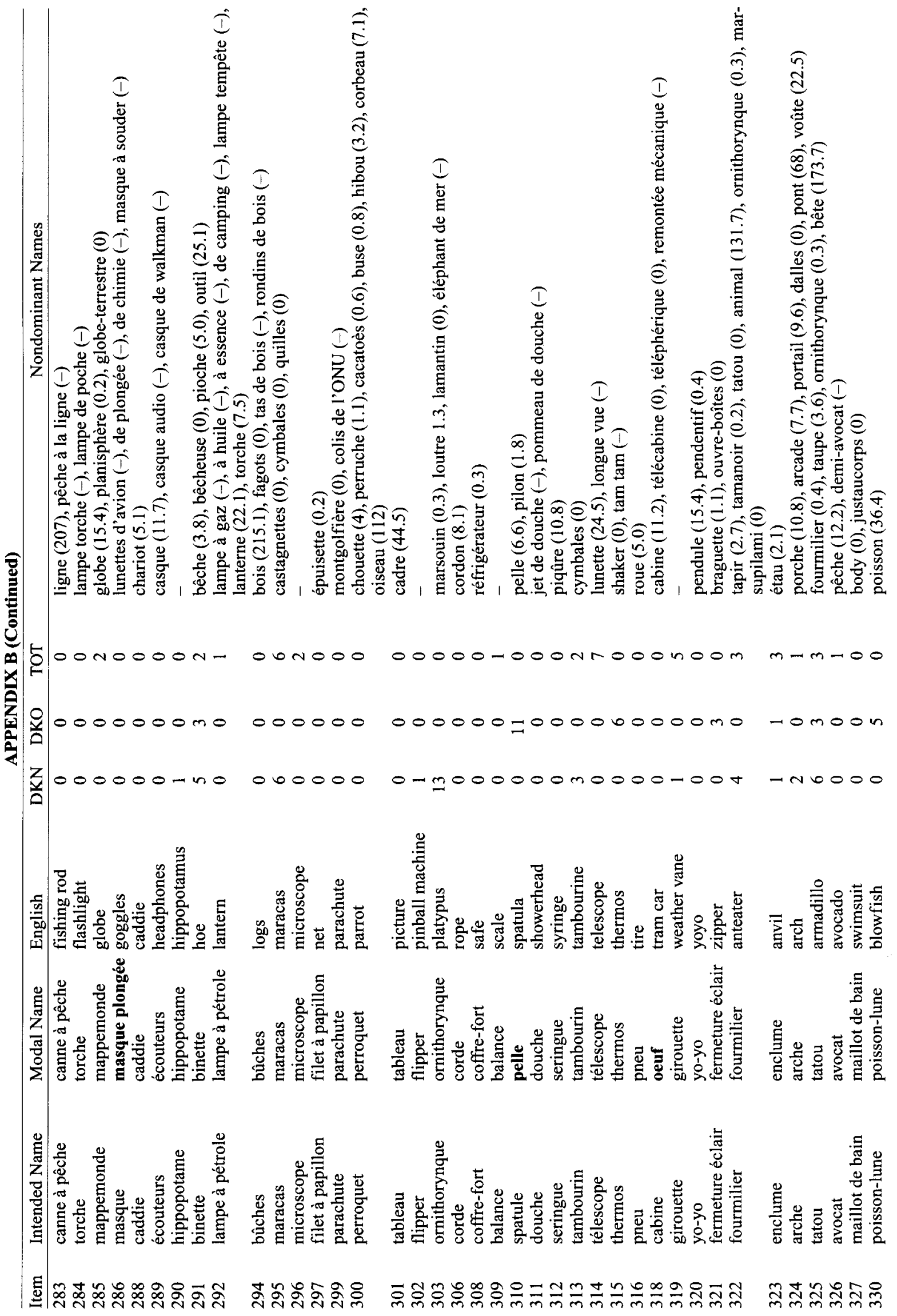




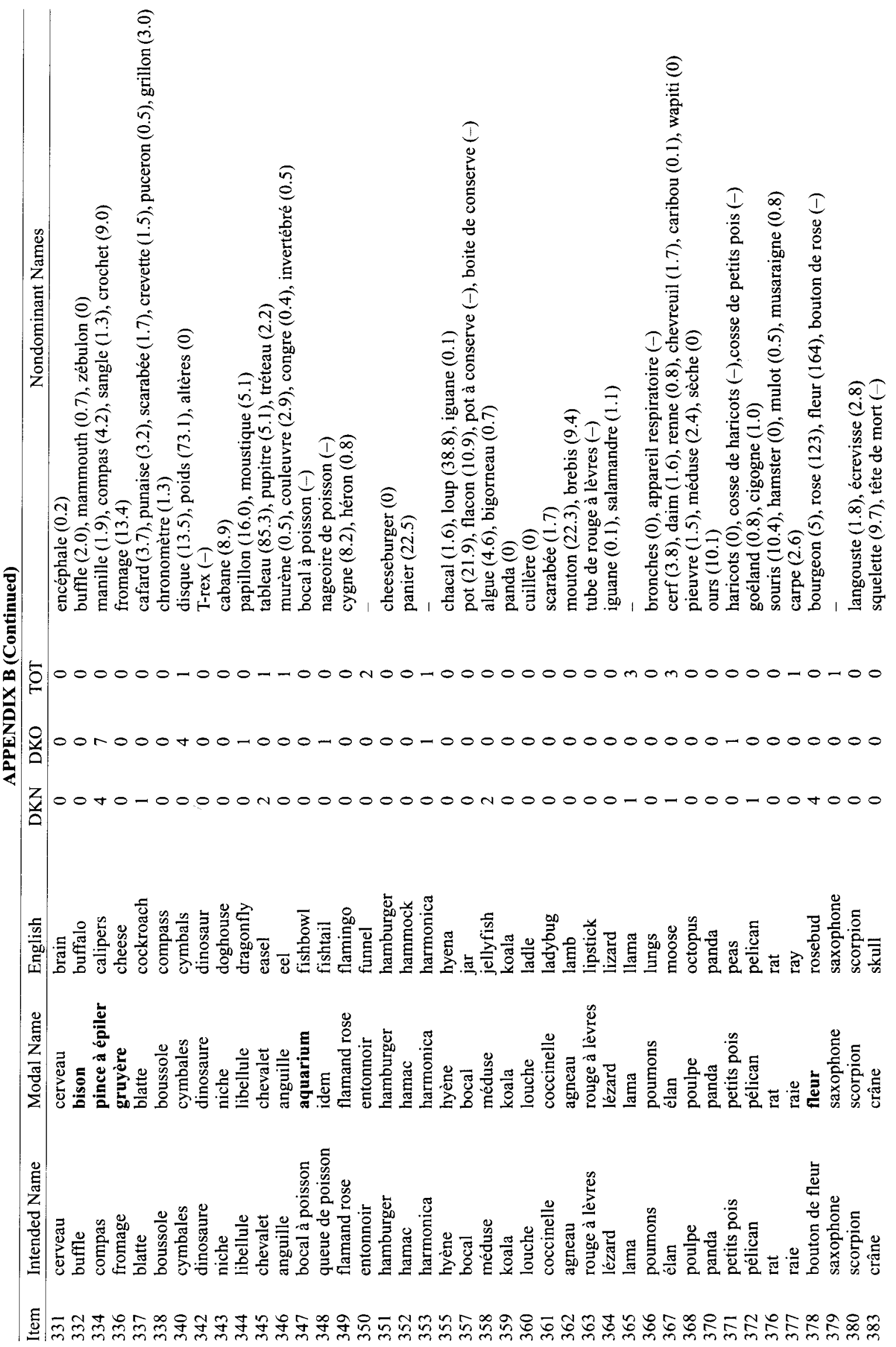




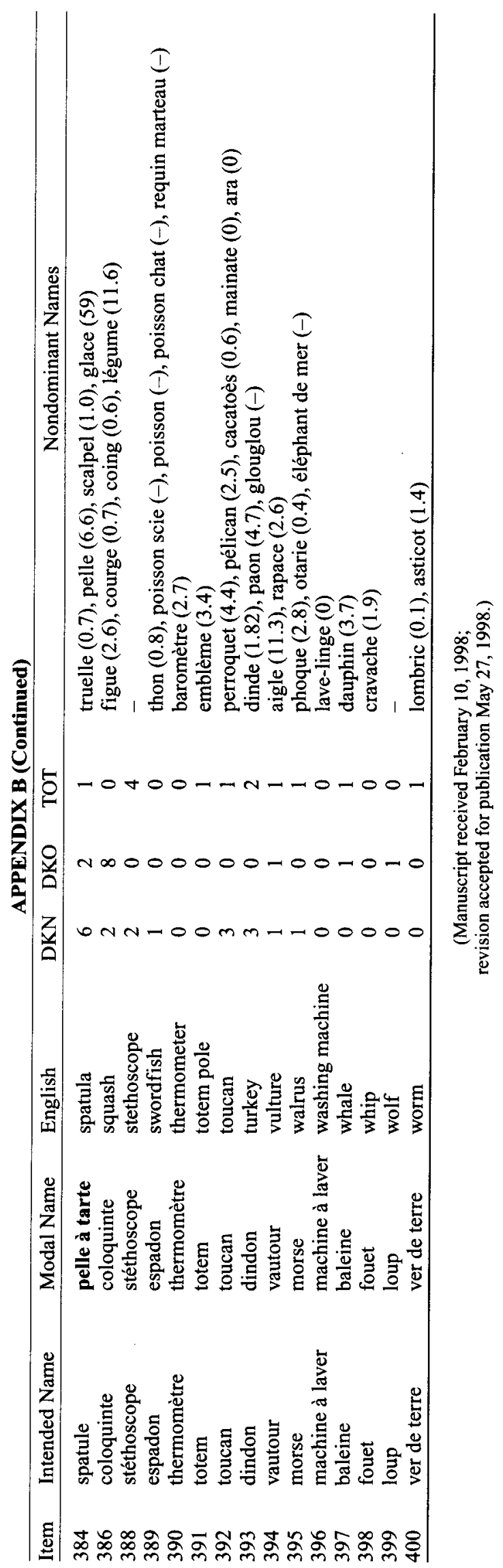

